\title{
The influence of expansive cement on the mechanical, physical, and microstructural properties of hybrid-fiber-reinforced concrete
}

\author{
Vahid Afroughsabet ${ }^{\mathrm{a}, \mathrm{b}, *}$, Guoqing Geng ${ }^{\mathrm{b}}$, Alexander Lin ${ }^{\mathrm{b}}$, Luigi Biolzi ${ }^{\mathrm{a}}$, Claudia P. Ostertag ${ }^{\mathrm{b}}$, \\ Paulo J.M. Monteiro ${ }^{\mathrm{b}}$ \\ ${ }^{\text {a }}$ Department of Architecture, Built Environment and Construction Engineering, Politecnico di Milano, Italy \\ ${ }^{\mathrm{b}}$ Department of Civil and Environmental Engineering, University of California, Berkeley, USA
}

\begin{abstract}

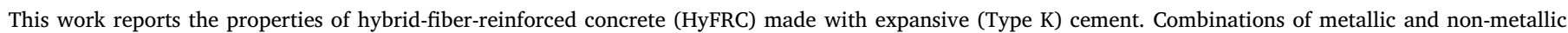

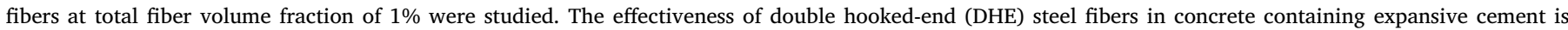

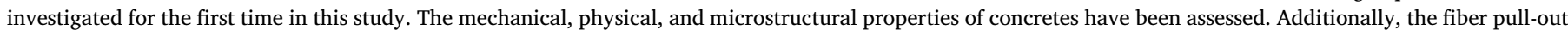

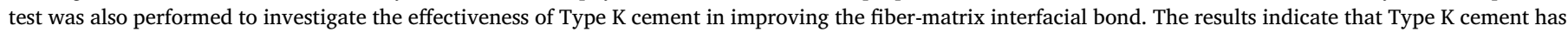

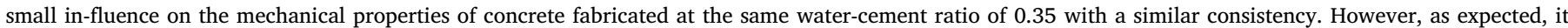

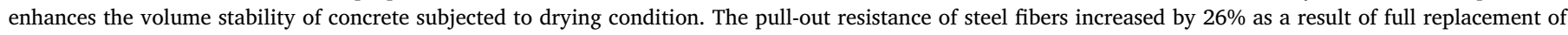

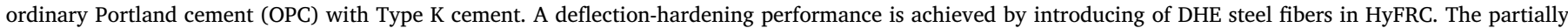

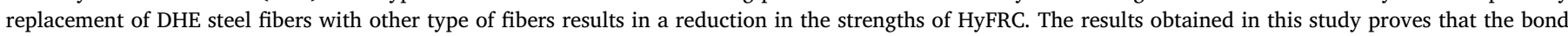

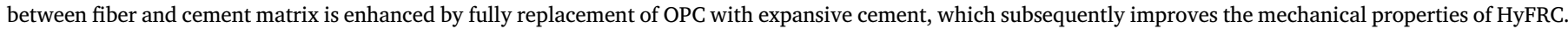

Keywords:

Expansive cement

Hybrid-fiber-reinforced concrete

Double hooked-end steel fibers

Fiber pull-out resistance

Drying shrinkage

Microstructural properties

\section{Introduction}

Concrete, with a yearly consumption of more than 25 billion tons [1], is the most used construction material in the world. The durability of concrete is an important concern for engineers to increase its serviceability and reduce the cost of maintenance [2]. Obviously, the presence of cracks in concrete can accelerate the penetration of harmful agents like chloride and sulfate ions, which subsequently degrade the service life of concrete structures [3]. The high amount of binder which is required to design high performance concrete (HPC) as well as exposure to dry climate, increase the possibility of crack formation and drying shrinkage $[4,5]$. Hence, controlling the shrinkage deformation as a source of cracks in concrete is of great interest for the concrete industry to expand the structural uses of concrete for specific applications [6]. To overcome this weakness, different techniques have been adopted including the replacement of ordinary Portland cement (OPC) with expansive cement, the addition of shrinkage reducing admixtures (SRA), expansive agent (EA), surface treatment, and introducing fibers $[7,8]$. The addition of EA in concrete can result in shrinkage- compensating concrete (SHCC) and self-stressing concrete, depending on the type and the content of EA $[9,10]$. The magnitude of the final expansion is the dominant factor that influencing the properties of expansive concrete that is larger in self-stressing concrete [11,12]. Type $\mathrm{K}$ cement is a modified Portland cement containing ye'elimite $\left(\mathrm{C}_{4} \mathrm{~A}_{3} \mathrm{~S}\right)$, gypsum $\left(\mathrm{CaSO}_{4}\right)$, and lime $(\mathrm{CaO})$ as its main components. It was reported that the addition of EA based on ye'elimite had insignificant influence on the mechanical properties of concrete, while a reduction up to $80 \%$ was occurred in the autogenous shrinkage [13].

As previously mentioned, another possible solution for controlling crack extension is through reinforcement of the concrete with fibers $[14,15]$. Reinforcing of concrete with single or combined used of discrete fibers not only increase the mechanical properties like splitting tensile, flexural and toughness of concrete [16-18] but also improve some durability performance $[19,20]$. The role of fibers is different in composites based on their properties like fiber type, size, aspect ratio, and modulus of elasticity. Basically, longer fibers would be more effective in resisting against macro-cracks and delaying crack opening, while micro fibers mainly postponing the initiation of micro-cracks

* Corresponding author. Department of Architecture, Built Environment and Construction Engineering, Politecnico di Milano, Italy.

E-mail address: vahid.afroughsabet@polimi.it (V. Afroughsabet). 
[21]. Obviously, the inclusion of a given fiber type can be effective only in a limited dimension of crack size [22]. Hence, hybridization of two or more precisely selected fibers with different sizes and types can develop more attractive engineering properties [23-25]. Researchers have mainly focused on the progress of hybrid-fiber-reinforced concrete (HyFRC) with fiber volume fraction more than $2 \%$ to produce highductility composites. Therefore, there are very limited experimental data about the hybridization of fibres at low fiber volume fraction, al-though it has many applications in the area of civil infrastructure.

The objective of the current study is to investigate the properties of concretes fabricated with Type $\mathrm{K}$ cement. There are very limited number of research that evaluated the effect of combined use of ex-pansive cement and fibers on the features of HPC [4,5,26-28]. There-fore, this study is aimed at developing new HyFRC with combinations of metallic and non-metallic fibers at low fiber volume fraction (less than 1\%). The effectiveness of double hooked-end steel fibers in expansive concrete is investigated for the first time in this work. Five different batches of concrete were fabricated to characterize their performance. The compressive strength, splitting tensile strength, flexural behavior, drying shrinkage, water absorption, and microstructural properties of concrete by means of Scanning electron microscopy (SEM) were determined. Additionally, four different mortar mixes were prepared to study the effectiveness of Type $\mathrm{K}$ cement in improvement of fiber-matrix interfacial bond and the effect of microfibers on the pull-out resistance of steel fibers. Finally, the hydration products of two types of cement were evaluated by means of X-ray diffraction (XRD) method at different curing ages of 7, 28, and 56 days. The findings of this research have the potential to contribute toward expanding the use of HyFRC made with expansive cement to different structural applications.

\section{Experimental program}

\subsection{Characteristics of materials}

ASTM Type II/V Portland cement and Type K expansive cement with specific gravity of 3.15 and 3.1 were used in conventional concrete (CC) and shrinkage-compensating concrete (SHCC), respectively. Crushed gravel with a nominal maximum size of $19 \mathrm{~mm}$, water ab-sorption of $1.24 \%$, and specific gravity of 2.74 and sand with a fineness modulus of 2.9 , water absorption of $1.1 \%$, and specific gravity of 2.65 were used. Both crushed gravel and sand were employed at an equal volume fraction of $50 \%$. A MasterGlenium 7500, produced by BASF factory was used in all concrete mixes as a superplasticizer. Moreover, a RECOVER hydration stabilizer was used in mixes containing expansive cement to delay the setting time of those concretes. Double hooked-end (DHE) and hooked-end (HE) steel fibers provided from Dramix and polyvinyl alcohol (PVA) fibers that was supplied by Kuraray were em-ployed in this study. The geometry and the properties of fibers are provided in Table 1.

\subsection{Concrete mixtures and mixing procedure}

Two plain concrete mixtures with different types of cement and three fiber-reinforced concrete (FRC) were cast at the same water-ce-ment ratio of 0.35 , and constant cement content of $450 \mathrm{~kg} / \mathrm{m}^{3}$. The mix proportions of different mixes were listed in Table 2 . In that table, the amount of superplasticizer and hydration stabilizer are shown as percentage of cement content. To achieve a homogeneous concrete, the following mixing procedure was selected. First, the coarse and fine aggregate in addition to the cement were mixed for $2 \mathrm{~min}$. Then, the mixing water including the superplasticizer and hydration stabilizer (if applicable) was added to the dry materials and mixed for another $3 \mathrm{~min}$. For FRC, the fibers were added gradually to the concrete and mixed for another $5 \mathrm{~min}$ to ensure the good distribution of fibers. To determine the workability of fresh concrete, slump tests were per-formed as per ASTM C143 [29] during the preparation of the concrete mixes. Finally, the specimens were molded with different dimensions that matched the requirements of their standards test. They were de-molded after approximately $24 \mathrm{~h}$ and then immersed in lime-saturated water at $23{ }^{\circ} \mathrm{C}$ until their testing ages. In addition to concrete mixes, two cement pastes at water-cement ratio of 0.35 with different types of cements were prepared for analyzing the hydration products of har-dened cement paste by means of XRD at different curing ages of 7, 28, and 56 days. Moreover, four mortar mixes with water-cement ratio of 0.35 have been prepared by modification of concrete mixes and elim-ination of coarse aggregate to study the pull-out behavior of fiber. The details of their mix proportions are given in Table 3.

\subsection{Testing methods}

Compressive strength and splitting tensile strength were conducted on the cylindrical specimens, with dimensions of $\Phi 100 \times 200 \mathrm{~mm}$ using a 3000-KN universal compression machine in accordance with ASTM C39 [30] and ASTM C496 [31], respectively. Prismatic beams with dimensions of $150 \times 150 \times 600 \mathrm{~mm}$ were used to measure the flexural performance of concrete in accordance with EN 14651 [32]. The adopted test setups and details of specimens of compressive strength test, splitting tensile test, and flexural test are shown in Fig. 1. For each reported test data, three specimens were prepared and they were tested at 7,28 , or 56 days of curing.

The free drying shrinkage test was performed on three prismatic specimens with dimensions of $75 \times 75 \times 285 \mathrm{~mm}$ in accordance with ASTM C157 [33] and the mean value is reported as drying shrinkage of different concrete mixes. The initial zero reading taken after demolding of samples. Then, the specimens immersed in lime-saturated water at 23 ${ }^{\circ} \mathrm{C}$ and $100 \%$ relative humidity for 27 days. The drying shrinkage was performed on the air stored specimens at a room with a relative humidity of $50 \%$ and temperature of $23{ }^{\circ} \mathrm{C}$, and consecutive readings were carried out up to 56 days.

The water absorption tests were performed on three cylindrical specimens in accordance with ASTM C642 [34] and the mean value is reported in this study. The water absorption of specimens was

Table 1

Properties of hooked-end steel and PVA fibers.

\begin{tabular}{|c|c|c|c|c|c|c|}
\hline Type and shape of fiber & Length $l(\mathrm{~mm})$ & Diameter $d(\mathrm{~mm})$ & Aspect ratio $l / d$ & Density $\left(\mathrm{g} / \mathrm{cm}^{3}\right)$ & Tensile strength $\left(\mathrm{N} / \mathrm{mm}^{2}\right)$ & Picture of fibers \\
\hline Double hooked-end steel (DHE) & 60 & 0.9 & 65 & 7.8 & 2300 & \\
\hline Hooked-end steel (HE) & 35 & 0.55 & 65 & 7.8 & 1050 & \\
\hline Polyvinyl alcohol (PVA) & 12 & 0.039 & 300 & 1.3 & 1600 & \\
\hline
\end{tabular}


Table 2

Mix proportions of concrete mixes.

\begin{tabular}{|c|c|c|c|c|c|c|c|c|c|c|c|c|c|}
\hline \multirow[t]{3}{*}{ Mix No. } & \multirow[t]{3}{*}{ Mixture ID } & \multirow[t]{3}{*}{$\mathrm{W} / \mathrm{B}$} & \multirow{3}{*}{$\begin{array}{l}\text { Water } \\
\left(\mathrm{kg} / \mathrm{m}^{3}\right)\end{array}$} & \multicolumn{2}{|c|}{ Cement } & \multirow[t]{3}{*}{ Fine Agg. } & \multirow[t]{3}{*}{ Coarse Agg. } & \multicolumn{3}{|c|}{ Fiber volume fraction (\%) } & \multirow[t]{3}{*}{ SP (\%) } & \multirow[t]{3}{*}{ HS (\%) } & \multirow[t]{3}{*}{ Slump $(\mathrm{cm})$} \\
\hline & & & & OPC & Type K & & & \multirow[b]{2}{*}{ DHE } & \multirow[b]{2}{*}{ HE } & \multirow[b]{2}{*}{ PVA } & & & \\
\hline & & & & & & & & & & & & & \\
\hline 1 & $\mathrm{CC}$ & 0.35 & 157.5 & 450 & - & 901 & 936 & - & - & - & 1.0 & - & 22 \\
\hline 2 & SHCC & & 157.5 & - & 450 & 898 & 933 & - & - & - & 1.2 & 0.2 & 24 \\
\hline 3 & DHE1 & & 157.5 & - & 450 & 884 & 919 & 1.0 & - & - & 1.5 & 0.2 & 25 \\
\hline 4 & DHE0.5 + PVA0.5 & & 157.5 & - & 450 & 884 & 919 & 0.5 & - & 0.5 & 1.8 & 0.2 & 14 \\
\hline 5 & DHE0.5 + HE0. $3+$ PVA0. 2 & & 157.5 & - & 450 & 884 & 919 & 0.5 & 0.3 & 0.2 & 1.8 & 0.2 & 18 \\
\hline
\end{tabular}

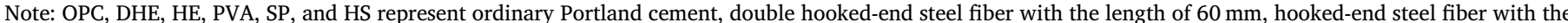

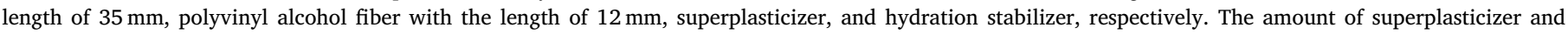
hydration stabilizer are shown as percentage of cement content.

Table 3

Mix proportions of mortar mixes.

\begin{tabular}{|c|c|c|c|c|c|c|c|c|}
\hline \multirow[t]{3}{*}{ Mix No. } & \multirow[t]{3}{*}{ Mixture ID } & \multirow[t]{3}{*}{ W/C } & \multicolumn{2}{|c|}{ Cement } & \multirow[t]{3}{*}{ Water } & \multirow[t]{3}{*}{ Sand } & \multirow{3}{*}{$\begin{array}{l}\text { PVA } \\
\text { fiber } \\
(\%)\end{array}$} & \multirow[t]{3}{*}{ SP (\%) } \\
\hline & & & OPC & Type K & & & & \\
\hline & & & \multicolumn{2}{|c|}{$\left(\mathrm{kg} / \mathrm{m}^{3}\right)$} & & & & \\
\hline 1 & $\begin{array}{l}\text { Type II/V- } \\
\text { Plain }\end{array}$ & 0.35 & 691.5 & - & 240.1 & 1381.6 & - & 0.40 \\
\hline 2 & $\begin{array}{l}\text { Type K- } \\
\text { Plain }\end{array}$ & & - & 686.6 & 241.1 & 1368.6 & - & 0.80 \\
\hline 3 & $\begin{array}{l}\text { Type II/V- } \\
1 \% \text { PVA }\end{array}$ & & 684.4 & - & 237.7 & 1367.5 & 1 & 0.56 \\
\hline 4 & $\begin{array}{l}\text { Type K- } \\
\text { 1\%PVA }\end{array}$ & & - & 679.6 & 238.6 & 1354.6 & 1 & 0.90 \\
\hline
\end{tabular}

calculated using the difference between the weights of oven dried samples and specimens that were immersed in the water tank for $30 \mathrm{~min}$ and 7 days, and correspond to early and ultimate water ab-sorption, respectively.

The fiber pull-out test was conducted on cylindrical samples with diameter and height of $37.5 \mathrm{~mm}$. The embedment length of steel fiber was $19 \pm 0.5 \mathrm{~mm}$. The fiber pull-out test was carried out at 28 days and three specimens were prepared for each mixes. The single fiber pull-out test setup is shown in Fig. 2. To observe the micro-cracking process of pull-out samples by a microscope, the following technique was used. First, the samples were kept in a vacuum impregnation for the period of $24 \mathrm{~h}$ to ensure that air have been sucked out from the mortar. Then, an epoxy was poured on the top surface of samples and leaved it for a while to allow epoxy be penetrated inside the free spaces of mortar. After 2 days that epoxy got hardened enough, the samples were cut along their fiber axis. Afterwards, the side of cut sample in-cluding the injected epoxy was selected to be polished carefully and reach the right position where the steel fiber was in the mortar. The polishing of samples stopped as soon as a clear appearance of fiber

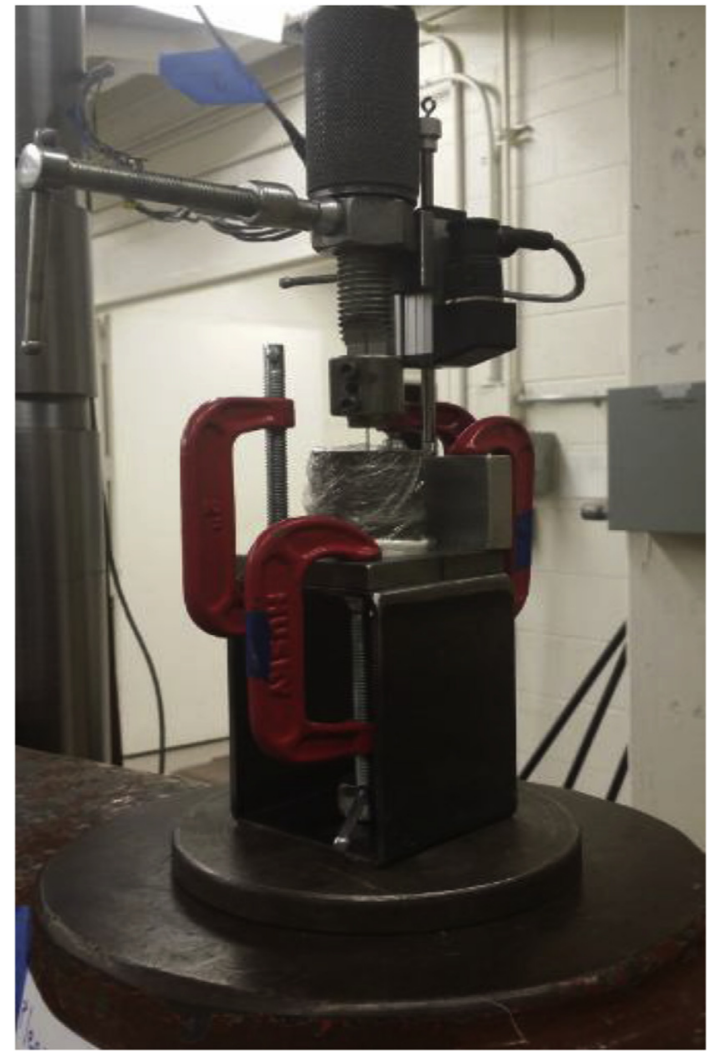

Fig. 2. Test setup for single fiber pull-out test.

channel filled with hardened epoxy was seen.

The unreacted cement powders, as well as hydrated pastes of selected ages $(7,28$, and 56 days), were measured by X-ray Diffraction

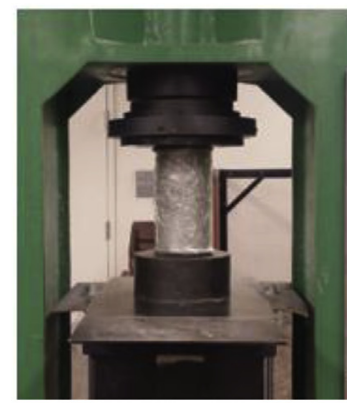

(a)

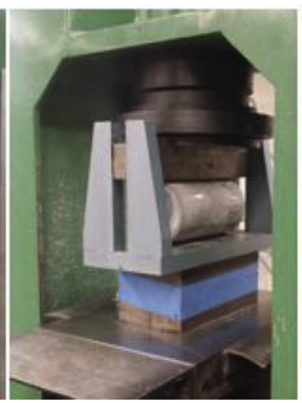

(b)

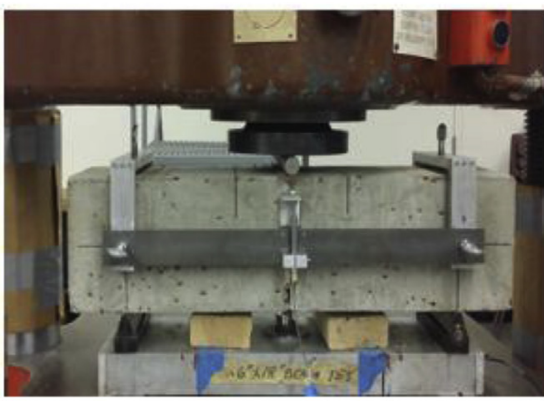

(c)

Fig. 1. Test setups for: (a) compressive strength test, (b) splitting tensile test, (c) flexural test. 


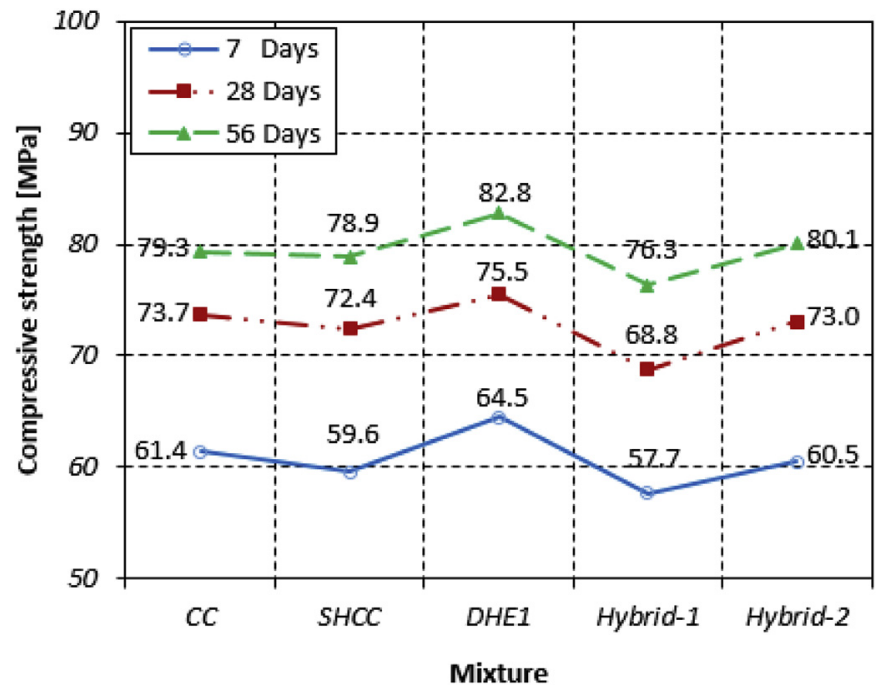

Fig. 3. Compressive strength of different concrete mixes (Hybrid$1=$ DHE0.5 + PVA0.5, and Hybrid-2 = DHE0.5 + HE0.3 + PVA0.2).

(XRD). The hydrated paste were hand-grinded using a ceramic mortar and pestle. The sample were immediately sent to XRD measurements and therefore no special care was taken to stop the hydration. A PANalytical X'Pert Pro diffractometer was used for the XRD measurement, operating at $40 \mathrm{keV}$ and $40 \mathrm{~mA}$ with a Cobalt anode. The 2-theta scanning range was between $5^{\circ}$ and $80^{\circ}$, with a step width of $0.0167^{\circ}$ and total collection time of $1 \mathrm{~h}$. Software HighScore (Plus) was used to identify the peak positions. This study also used a ZEISS EVO MA10 SEM to collect microscale morphology of the samples. The secondary electron (SE) mode was used to study a fracture surface, and the backscattered electron (BSE) mode was used to image a well-polished surface. The samples were carbon-coated prior to the SEM experiment, to avoid charging problem.

\section{Results and discussions}

\subsection{Compressive strength}

The compressive strength results of different mixes at curing ages of 7, 28, and 56 days is shown in Fig. 3. The results indicate that the full replacement of OPC with Type K cement has no significant influence on the compressive strength of concrete, and a slight reduction up to $3 \%$ was occurred. It may be attributed to the formation of higher ettringite in concrete with expansive cement which is the source of volume expansion and can create some micro-cracks in the body of concrete that subsequently reduce the strength compared to conventional concrete. A slight reduction in the strength of concrete fabricated by expansive cement has been observed by other researchers [35,36] as a result of aforementioned phenomena. It can be seen that the inclusion of $1 \% \mathrm{DHE}$ steel fibers slightly increased the compressive strength of SHCC. For instance, the compressive strength of concrete reinforced with 1\%DHE steel fibers were $8 \%, 4 \%$, and $5 \%$ higher than those of CC at 7,28 , and 56 days, respectively. DHE steel fibers, owing to their high elastic modulus and particular shape that restricts the propagation of cracks, alters the tendency of cracks, and subsequently improves the compressive strength of concrete [37]. However, the substitution of $0.5 \%$ DHE steel fibers volume content with PVA fibers led to a slight reduction in the compressive strength of concrete. There are several factors including the fiber content, fiber type, fiber size, and porosity of cement matrix that affect the compressive strength of FRC. The reduction attained in the strength of DHE0.5 + PVA0.5 mix can be attributed to the higher porosity of this mix compared to that of SHCC that becomes the dominant factor in this mix. The results demonstrate that the strength

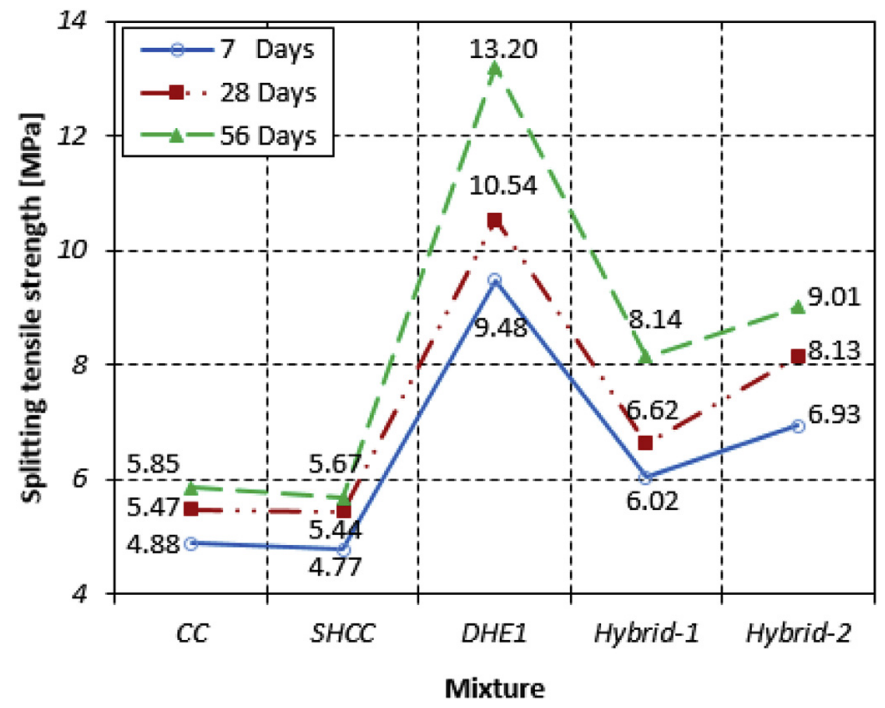

Fig. 4. Splitting tensile strength of different concrete mixes (Hybrid$1=$ DHE0.5 + PVA0.5, and Hybrid-2 = DHE0.5 + HE0.3 + PVA0.2).

of DHE0.5 + HE0.3 + PVA0.2 mix is slightly higher than that of the corresponding mix without fibers (SHCC) at all curing ages considered in this study.

\subsection{Splitting tensile strength}

The splitting tensile strength of the different mixes prepared in this study is shown in Fig. 4. Similarly, the splitting tensile strength of concrete produced with Type $\mathrm{K}$ cement is reduced by only $3 \%$ compared to that of CC. The results indicate that the incorporation of fibers significantly improves the splitting tensile strength of concrete. Among different mixes that considered in this study, the highest strength was achieved by the mix containing 1\% DHE steel fibers. The splitting tensile strength of this mix were $99 \%, 94 \%$, and $133 \%$ higher than those of CC at 7, 28, and 56 days, respectively. Even though hybridization of the fibers resulted in a reduction in the splitting tensile strength of concrete compared to DHE1 mix; however, the strength of HyFRC mixes is still significantly higher than that of the plain concrete. For instance, the splitting tensile strength of DHE0.5 + PVA0.5 and DHE0.5 + HE0.3 + PVA0.2 mixes increased by $22 \%$ and $49 \%$ at 28 days compared to that of SHCC, respectively. As it can be seen in Fig. 4, the effect of curing age on the improvement of splitting tensile strength is relatively higher in FRC compared to plain concrete. The presence of expansive cement in FRC resulted in a better bond between fibers and cement matrix over time due to self-stressing that consequently caused an increase in the splitting tensile strength of FRC. For instance, the splitting tensile strength of SHCC mix was increased by $14 \%$ and $19 \%$ at 28 and 56 days compared to its 7 days strength, respectively, while the average increase in FRC mixes was $13 \%$ and 35\%, respectively. This result has been verified by the results of single fiber pull-out test and SEM images that show the effectiveness of Type $\mathrm{K}$ cement in improvement of bond between fibers and cement matrix that are discussed in sections 3.6.2 and 3.7.2.

\subsection{Flexural performance}

\subsubsection{Flexural strength-CMOD curve}

The diagram of 28-day flexural strength-CMOD for different concrete mixes is shown in Fig. 5. As it can be seen in Fig. 5, the behavior of concretes without fibers was almost linear up to the maximum load, followed by a sharped descending branch up to failure point, then the beam specimens split into two separated parts. The results indicate that substitution of OPC with Type K cement resulted in $4 \%$ increase in the 


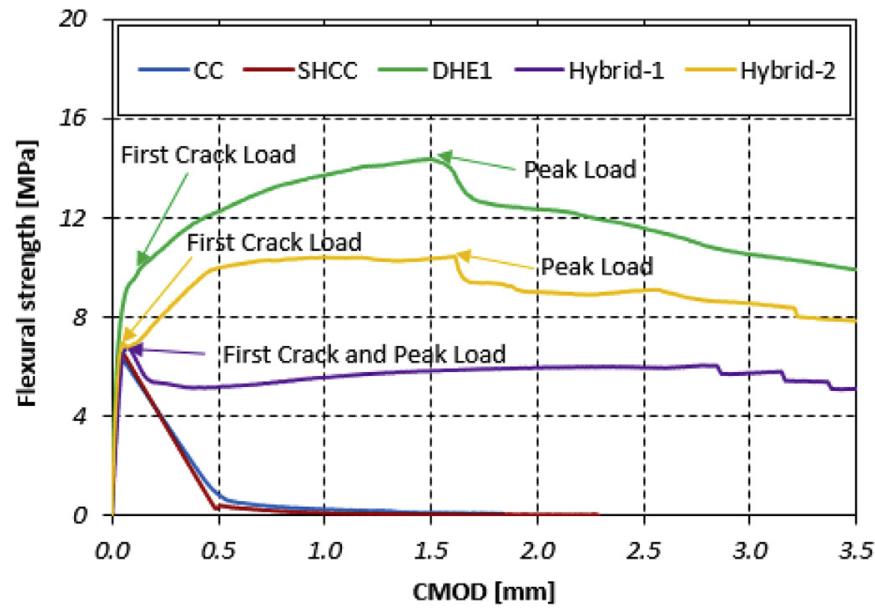

Fig. 5. 28-days flexural strength-CMOD curves of different concrete mixes (Hybrid-1 = DHE0.5 + PVA0.5, and Hybrid-2 = DHE0.5 + HE0.3 + PVA0.2).

flexural strength. It has been reported that the addition of expansive agent in concrete led to an almost similar flexural strength compared to ordinary concrete [27]. On the other hand, the results of fiber-reinforced concretes illustrate that the addition of fibers remarkably improved the post-cracking behavior of FRC with an extensive cracking process between first crack load and peak load. Once the first crack was occurred, the fibers bridging the crack resisted the load and prevented further crack propagation. This resulted in an increase in the load that could be resisted to loads beyond the first cracking load. Fig. 5 shows that the best performance has been achieved by incorporation of $1 \%$ DHE steel fibers in concrete. The inclusion of 1\% DHE steel fibers in concrete led to an increase in the load bearing capacity after first crack and the flexural strength increased up to CMOD equal to $1.5 \mathrm{~mm}$. Then, a relatively big crack occurred in the beam and the flexural load gradually decreased. The excellent performance of this mix can be attributed to the ability of DHE steel fibers to carry the load after matrix cracks until further creation of cracks. The flexural load would be reduced due to the failure of fiber anchorage or debonding of fibers and the matrix [38-40]. However, the replacement of 0.5\% DHE steel fibers content with PVA fibers adversely affected the flexural performance of concrete compared to DHE1 mix, while its behavior was significantly better over that of plain concrete. The flexural strength of this mix was increased by only $4 \%$ compared to that of SHCC, and a drop in the flexural strength of concrete was observed after appearance of first crack. Then, a relatively flat behavior was seen in the load bearing capacity up to CMOD equal to $3.5 \mathrm{~mm}$. When the flexural stress at the fiber-matrix interface has surpassed the bond developed by the matrix, the fibers are either slipping or being unbounded. As a result, the only mechanism that contribute to improve the strength of cracked section is through mechanical anchorage. Since, PVA fibers are straight and have lower length compared to steel fibers, they can bridge mainly the micro-cracks and have minor influence on the flexural strength. The results demonstrate that hybridization of three different kind of fibers increased the flexural strength by $60 \%$ compared to that of the SHCC. Similar to DHE1 mix, combination of fibers in DHE0.5 + HE0.3 + PVA0.2 mix led to a load-deflection hardening behavior. According to EN 14651 [32], limit of proportionality (LOP) is stress at the tip of the notch which is assumed to act in an un-cracked mid-span section with linear stress distribution of a prismatic beam subjected to the centre-point load. The CMOD and flexural strength corresponding to this point are designated as $\mathrm{CMOD}_{\mathrm{LOP}}$ and $\mathrm{f}_{\mathrm{LOP}}$, respectively. The ultimate flexural strength commonly known as modulus of rupture (MOR) is defined as the point where softening happens after the LOP. The CMOD and flexural strength corresponding to this point are designated as $\mathrm{CMOD}_{\mathrm{MOR}}$ and $\mathrm{f}_{\mathrm{MOR}}$, respectively. The results indicate

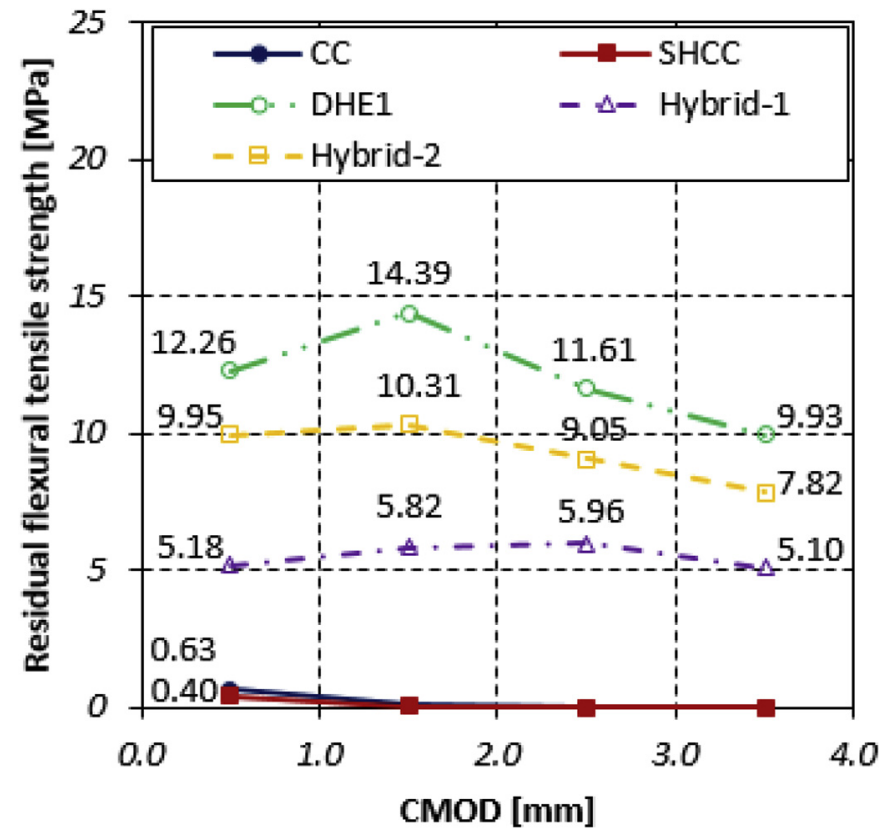

Fig. 6. Residual flexural tensile strength of different concrete mixes (Hybrid$1=$ DHE0.5 + PVA0.5, and Hybrid-2 = DHE0.5 + HE0.3 + PVA0.2).

that the $\mathrm{CMOD}_{\mathrm{MOR}}$ corresponding to the peak load for plain concretes and DHE0.5 + PVA0.5 mix was similar to CMOD $_{\text {LOP. }}$. However, the $\mathrm{CMOD}_{\mathrm{MOR}}$ for DHE1 and DHE0.5 + HE0.3 + PVA0.2 mixes were 1.5 and $1.6 \mathrm{~mm}$, respectively that were 15 and 26.6 times of their CMO$\mathrm{D}_{\mathrm{LOP}}$. For these mixes, the $\mathrm{f}_{\mathrm{MOR}}$ increased by $52 \%$ and $50 \%$ compared to their $\mathrm{f}_{\mathrm{LOP}}$, respectively. An increase of up to $46 \%$ was also observed in the $f_{\text {LOP }}$ of FRC compared to that of SHCC. The research finding of this study demonstrate that all the HyFRC considered in this work show a deflection hardening behavior and conventional steel bar can be replaced by randomly distributed fiber according to fib Model Code 2010 [41]. Therefore, HyFRC were developed in this study can be of high interest for design of structural member that subjected to bending load.

\subsubsection{Residual flexural tensile strength and flexural toughness}

The residual flexural tensile strength for different concrete mixes is shown in Fig. 6. As can be seen in Fig. 6, the residual flexural strength of plain concretes are quite similar and since these samples split in two separated parts, the results beyond CMOD of $0.5 \mathrm{~mm}$ were not provided. The results indicate that the inclusion of fibers and specifically DHE steel fibers significantly improves the residual flexural strength of concrete. The results also show that the hybridization of fibers resulted in a reduction in the residual flexural strength compared to that of the mix containing 1\% DHE steel fibers. For example, the residual flexural strength of DHE0.5 + PVA0.5 mix reduced by $58 \%, 60 \%, 49 \%$, and $49 \%$ at CMOD of $0.5,1.5,2.5$, and $3.5 \mathrm{~mm}$, respectively compared to those of DHE1 mix. DHE steel fibers due to their particular shape resist significantly against the propagation of cracks, absorbed more energy, and caused an increase in the load carrying capacity. However, the inclusion of PVA fibers in the mixes that reinforced with steel fibers was very effective to improve the post-cracking behavior of concrete and avoid the propagation of micro-cracks. For instance, the residual flexural strength of DHE0.5 + PVA0.5 mix at CMOD of 0.5, 1.5, 2.5, and 3.5 were $5.18,5.82,5.96$, and $5.10 \mathrm{MPa}$, respectively. This result show that the main influence of micro fibers like PVA is to enhance the toughness of concrete instead of increasing the peak flexural load. The full replacement of OPC with Type $\mathrm{K}$ cement slightly reduced the toughness of concrete. On the other hand, the introducing of fibers of any type and combination has a remarkable effect on the improvement of toughness. The highest toughness was attained by the mix containing 


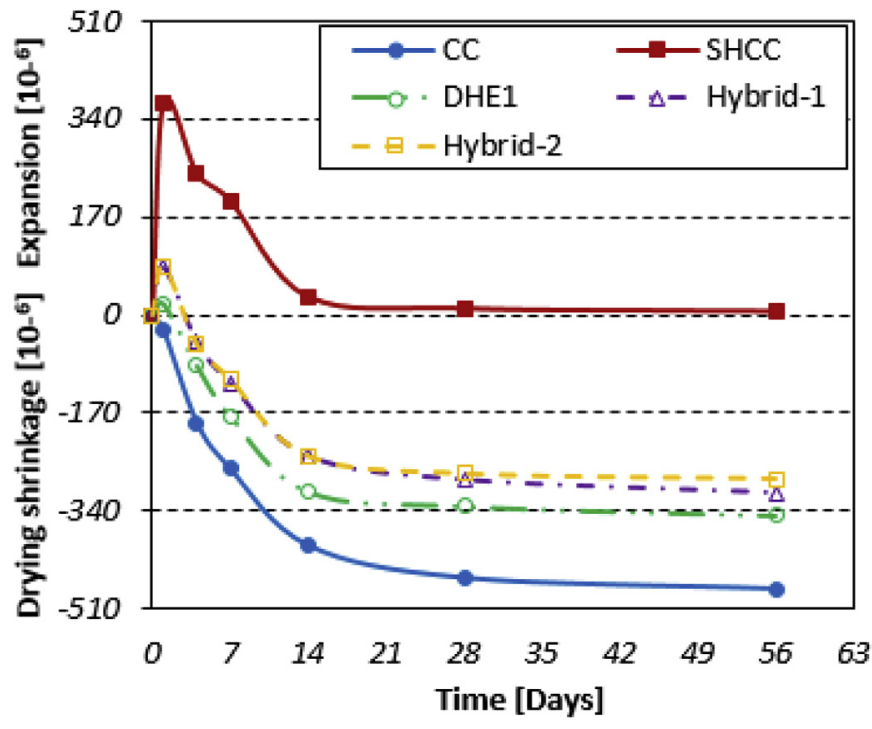

Fig. 7. Drying shrinkage of different concrete mixes (Hybrid1 = DHE0.5 + PVA0.5, and Hybrid-2 = DHE0.5 + HE0.3 + PVA0.2).

1\% DHE steel fibers that its toughness was 22.7 times compared to SHCC. This is followed by DHE0.5 + HE0.3 + PVA0.2 and DHE0.5 + PVA0.5 mixes that their toughness were 10.7 and 19.5 times, respectively over that of SHCC.

\subsection{Drying shrinkage}

The result of drying shrinkage for different concrete mixes is shown in Fig. 7. The results indicate that the replacement of OPC with Type $\mathrm{K}$ cement led to an expansion, while samples prepared with OPC experienced shrinkage over testing time. Fig. 7 shows a great expansion (369 $\mu \mathrm{m} / \mathrm{m}$ ) that occurred in SHCC after 1 day, whereas the shrinkage of CC samples was $27 \mu \mathrm{m} / \mathrm{m}$. This high value of early volume expansion in SHCC mix can be attributed to the high amount formation of et-tringite. The results also demonstrate that the replacement of OPC with Type $\mathrm{K}$ cement can compensate the shrinkage of concrete and the length change remained almost unchanged after 56 days. It was also observed that highest shrinkage among all mixes considered in this study was attained by CC that a shrinkage strain of $475 \mu \mathrm{m} / \mathrm{m}$ was happened at 56 days. As shown in Fig. 7, the inclusion of fibers of any type and fiber combination resulted in a reduction in the expansion of FRC made with Type $\mathrm{K}$ cement. However, an expansion strain up to $85 \mu \mathrm{m} / \mathrm{m}$ was ob-served in FRC at 1 day due to the presence of expansive cement. Thereafter, the expansion of concrete samples has been fully cancelled due to the restraining effect of fibers. The effectiveness of steel fibers in restraining the expansion of shrinkage-compensating concrete has been also shown by Paul et al. [42]. In another study, He et al. [43] studied the expansive deformation of self-stressing concrete reinforced with steel fibers. They pointed out that inclusion of fibers can fully eliminate the swelling of concrete resulted from the introducing of expansive agent. They hypothesized that this phenomenon would create a mutual interfacial stress between matrix and fibers and consequently leads to an internal homogeneous compressive prestress. Moreover, the im-proved chemical bond between fibers and cement matrix and subse-quently enhanced flexural performance of FRC can be attributed to the self-prestress effect. The results of present study in the sections of splitting tensile strength and single fiber pull-out test verified the abovementioned hypothesis. The results of FRC indicate that hy-bridization of fibers is a promising way to reduce the shrinkage de-formation of concrete. Among different FRC considered in this study, the lowest drying shrinkage was attained by DHE0.5 + HE0.3 + PVA0.2 mix. As cracks are initiated with small size

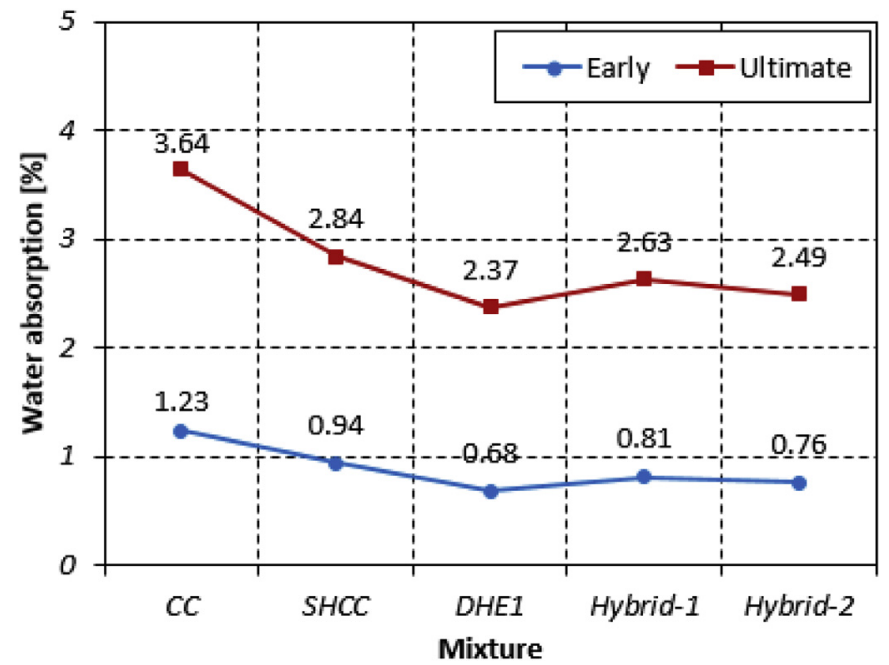

Fig. 8. Early and ultimate water absorption of different concrete mixes (Hybrid-1 = DHE0.5 + PVA0.5, and Hybrid-2 = DHE0.5 + HE0.3 + PVA0.2).

and later propagated with different sizes in the body of concrete, hybridization of fibers with various features, such as different lengths and modulus of elasticity, plays an important role in resisting cracking at different scales and causes lower shrinkage. It was also reported by Sun et al. [26] that combined use of PVA fibers and steel fibers can significantly inhibit the shrinkage of concrete compared to using monotype of steel fibers. The results also indicate that the shrinkage of all samples tends to stabilize after 14 days.

\subsection{Water absorption}

The ingress of destructive ions like chloride and sulfate into the concrete adversely affects the durability of concrete. Fig. 8 shows early (30 $\mathrm{min}$ ) and ultimate (7 day) water absorption of different concrete mixes. The SHCC samples had lower water absorption compared to that of the CC. The reduction were $24 \%$ and $22 \%$ for early and ultimate water absorption, respectively. This reduction can be attributed to the formation of higher amount of ettringite in mix containing Type K cement that fills the voids, leads to the discontinuity of pore network, and also improves the characteristics of cement matrix [44]. The finding of this research in microstructural observation confirmed the improved properties of cement matrix in SHCC mix. The results show that the addition of fibers reduced the water absorption of concrete with respect to SHCC irrespective of the fiber type and fiber hybridization. It was observed that the lowest water absorption was attained by the mix reinforced with $1 \%$ DHE steel fibers that its ultimate water absorption was $17 \%$ lower than that of SHCC. This reduction can be attributed to the ability of fibers to restrict the creation and propagation of cracks in the body of concrete that resulting in a reduced permeability [45]. The results illustrate that substitution of DHE steel fibers with PVA and HE steel fibers slightly increased the water absorption of concrete, while these concretes reached lower absorption compared to SHCC. This result suggests that the addition of PVA fiber content results in a rela-tively higher porosity compared to one reinforced by only steel fibers. The results of water absorption demonstrate a good correlation with the compressive strength test results, in which higher PVA fiber content led to a reduction in the strength of concrete.

\subsection{Compressive, splitting tensile, and pull-out test results of mortars}

\subsubsection{Compressive and splitting tensile strength}

The mechanical test results of different mortar mixes are listed in Table 4. The mixes with Type K cement showed slightly lower compressive and splitting tensile strength compared to that of mixes 
Table 4

Mechanical and fiber pull-out test results of mortar mixes.

\begin{tabular}{|c|c|c|c|c|c|}
\hline \multirow[t]{2}{*}{ Mix No. } & \multirow[t]{2}{*}{ Mixture ID } & \multirow[t]{2}{*}{ Compressive strength (MPa) } & \multirow[t]{2}{*}{ Splitting tensile strength (MPa) } & \multicolumn{2}{|l|}{ Pull-out } \\
\hline & & & & $\operatorname{Pmax}(\mathrm{N})$ & $\Delta$ peak $(\mathrm{mm})$ \\
\hline 1 & Type II/V-Plain & $63.5(2.3)$ & $5.9(4.2)$ & $418.1(3.6)$ & $0.75(4.1)$ \\
\hline 2 & Type K-Plain & $59.4(1.8)$ & $5.6(4.7)$ & $525.9(5.2)$ & $0.65(7.4)$ \\
\hline 3 & Type II/V-1\%PVA & $64.4(4.6)$ & $7.4(7.1)$ & $366.0(6.9)$ & $0.60(11.6)$ \\
\hline 4 & Type K-1\%PVA & $61.0(3.8)$ & $6.9(7.5)$ & $427.7(4.7)$ & $1.33(11.2)$ \\
\hline
\end{tabular}

Note: The number in the () shows the coefficient of variation (\%).

manufactured with OPC. These results are in good agreement with our finding for concrete mixes that has been already discussed. It was also observed that the addition of 1\% PVA fibers in both plain mortars led to an increase in the mechanical properties and particularly the splitting tensile strength. For instance, the compressive and splitting tensile strength of Type II/V-1\%PVA mix increased by $2 \%$ and $25 \%$, respectively compared to those of corresponding mix without fibers, while these increase for mortars with Type $\mathrm{K}$ cement were $3 \%$ and $23 \%$, respectively. This improvement can be related to the ability of fibers to restrict the formation and propagation of cracks in the body of concrete.

\subsubsection{Single fiber pull-out test}

The load versus displacement curve of different mortar mixes is depicted in Fig. 9 and pull-out test results are presented in Table 4. In this table, the maximum pull-out force is specified as Pmax, while the displacement corresponding to this point is designated as $\Delta$ peak. As can be seen in Fig. 9, a relatively similar trend was observed in the fiber pullout curves of different mortar mixes. The load versus displacement curves can be divided to three distinctive parts, in which each of them represent a specific behavior of fiber inside the mortar [46]. The hookedend of steel fiber including a straight part at the end that fol-lowed by an inclined part connected to the long straight steel fiber. Part a, represents a linear ascending branch that resulted from the plastic deformation of both parts of hooked-end. Afterwards, a descending branch was observed that followed by a second peak with a relatively lower pull-out force (part b). This peak corresponds to the bending of straight part of hookedend at the position where inclined part was in the beginning. Finally, fiber pull-out curve shows a relatively flat be-havior with a gradual reduction in the pull-out force that corresponds to the movement of steel fiber through the original channel of mortar after complete straightening of hooked-end (part c). The results indicate that the replacement of OPC with Type $\mathrm{K}$ cement has a positive influence on the pull-out force of mortar. It was observed that pull-out force in-creased by $26 \%$ as a result of the full replacement of OPC with Type K cement. This improvement can be attributed to the better bond that took place between steel fibers and cement matrix as a result of cement expansion and formation of self-prestress effect [43].

The results of FRC indicate that the reinforcement of plain mortars with 1\% PVA fibers led to a reduction in the peak load of pull-out force. It was observed that pull-out force of Type II/V-1\%PVA and Type K-1\% PVA mixes were $12 \%$ and $19 \%$ lower when compared to that of the corresponding plain mortar mixes. In fact, introducing microfibers in concrete either resulting in higher pull-out resistance due to the restriction of micro-cracks or reducing the pull-out resistance because of lower shrinkage that is not favorable for the bond between fiber and matrix [21]. The results of this study suggests that the pull-out resistance was reduced as a result of lower shrinkage in cement matrix that weakened the fiber-matrix bonding. This reduction can also be explained by the higher porosity of mixes containing PVA fibers compared to plain mortars. Indeed, the appearance of big voids around the hook counteracts the positive effect of PVA fibers to restrict the initiation of micro-cracks. This result has been confirmed by microscopic observation of cut surface that will be discussed in next section. As it can be seen in Fig. 9, the second peak reached a value almost similar to first peak in case of mortars reinforced with PVA fibers, while there was a big drop in the pull-out force of plain mortars after the first peak. Comparing the pull-out behavior of different mortars in part $\mathrm{c}$ indicate that the addition of PVA fibers resulted in an increase in the frictional stress between steel fibers and surrounding matrix. The coefficient of variation of pull-out test results is presented in Table 4. The results indicate that the scatter in pull-out test results and particularly mixes reinforced with $1 \%$ PVA fibers was high. This can be attributed to the increased porosity and air voids around the hooked-end of steel fiber embedded in mortar due to the presence of PVA fibers. Markovich et al.[46] studied single fiber pull-out from hybrid fiber-reinforced concrete. It was reported that the standard deviation for Pmax varied from $0.9 \%$ to $15.2 \%$. The findings of this study are in good agreement with their results.

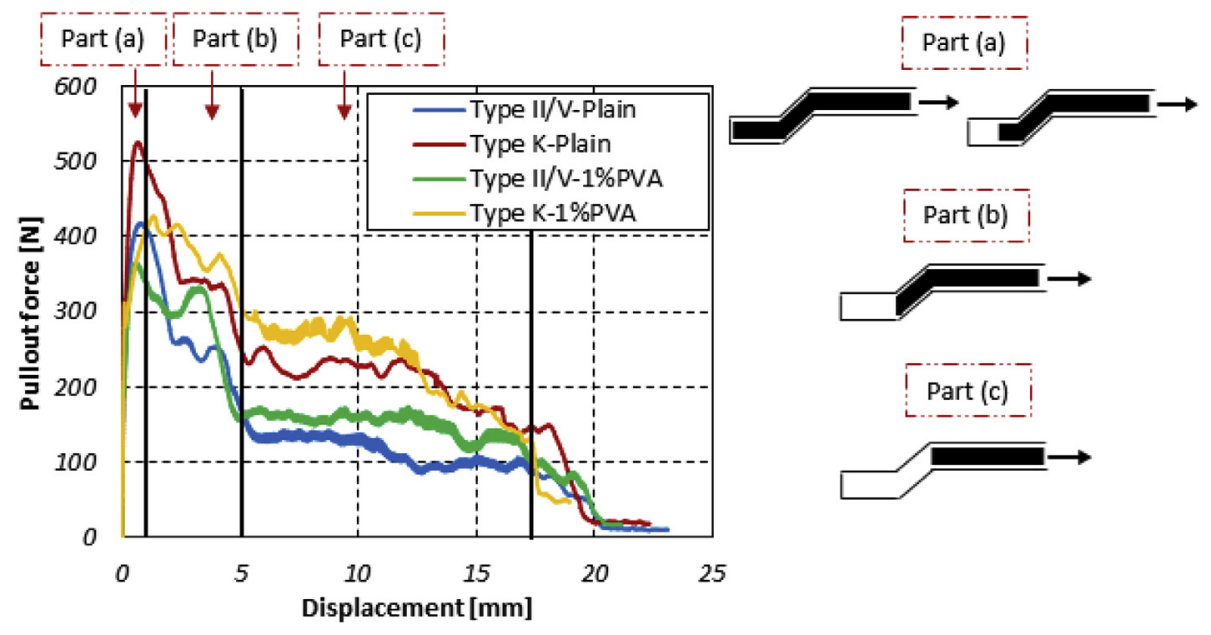

Fig. 9. Fiber pull-out curves versus displacement of different fiber-reinforced mortars. 

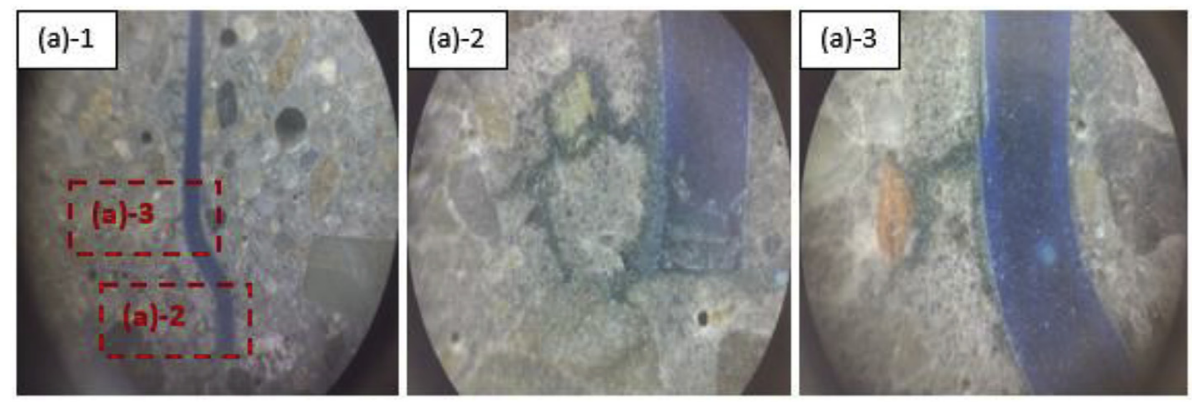

(a)
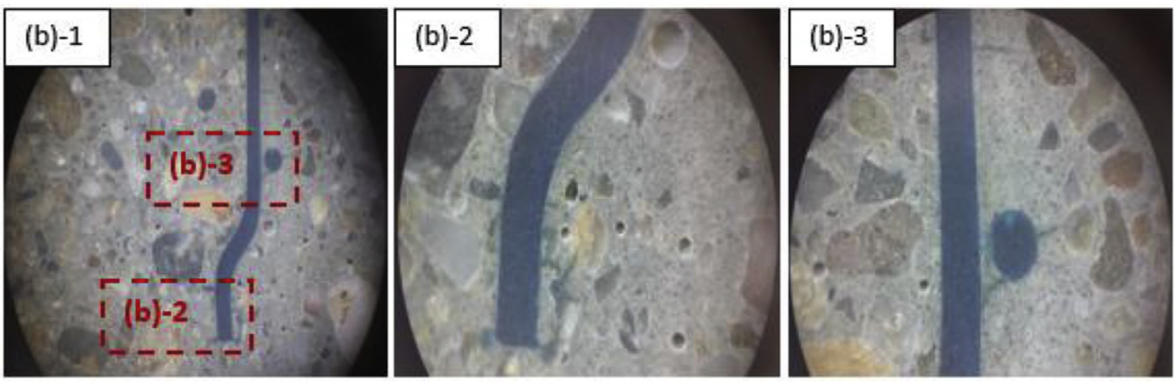

(b)
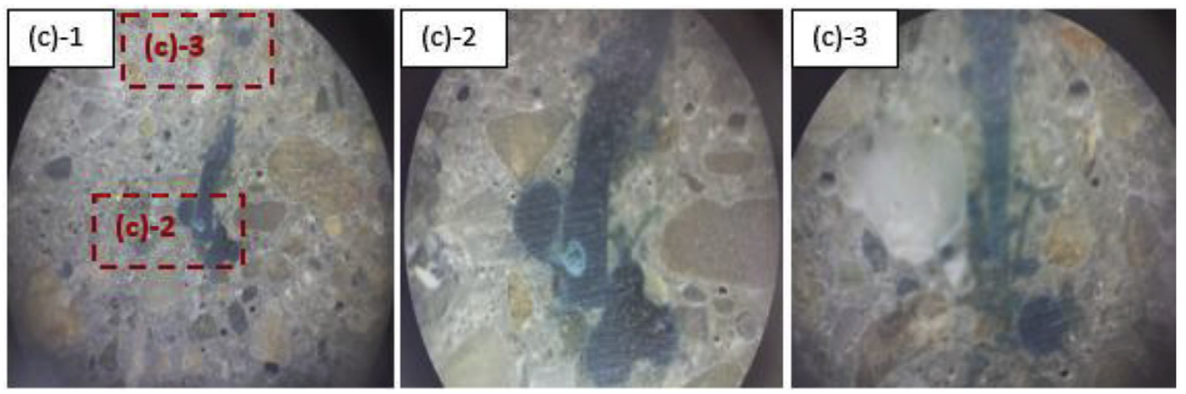

(c)

Fig. 10. Microscopic observation of micro-cracking process around the fiber hook of different fiber-reinforced mortars: (a) sample with Type II cement, (b) sample with Type K cement, (c) sample with Type K cement and reinforced with 1.0\% PVA fiber.

\subsubsection{Microscopic observation of pull-out samples}

Fig. 10 shows the microscopic observation of different samples after the fiber was pulled out. The plastic deformation of hook and slipping of fiber inside the channel led to the formation of micro-cracking around the fiber and particularly at the area closed to the hook in plain samples. There was no clear difference between the number and width of cracks in two different plain mortars. On the other hand, the addition of $1 \%$ PVA fibers in mortar increased the porosity of mortar and two big voids were observed very close to the hook in Type K-1\%PVA sample. As shown in previous section, the pull-out force of reinforced mortars was lower compared to that of plain mortars and it can be contributed to the appearance of these voids due to the less workability of mixes.

\subsection{Evidence from the microstructure}

\subsubsection{Components analysis from XRD measurements}

To track the phase change of at the microscale during hydration process, XRD was conducted to both types of paste at different hydration ages. As shown in Fig. 11(a), the diffractogram of anhydrous Type $\mathrm{K}$ cement contains strong diffraction peaks of ye'elimite and $\mathrm{CaSO}_{4}$, apart from the signals of $\mathrm{C}_{3} \mathrm{~S}$ and small quantity of $\mathrm{C}_{2} \mathrm{~S}$. As a result, the 7 days hydration product contains significant amount of ettringite, which contributes to the volume expansion of the paste. Another major crystalline phase in the hydration product is portlandite, which is from the hydration of $\mathrm{C}_{3} \mathrm{~S}$. It should be noted that, the intensity of $\mathrm{C}_{3} \mathrm{~S}$ peaks decreases rapidly in the first week, but the decrease clearly slows down thereafter. However the major peak of ye'elimite $\left(\sim 27.8^{\circ}\right)$ exhibits a continuous attenuating until complete absence in 28 days. As shown in Fig. 11(b), the Type II/V cement composed mainly of $\mathrm{C}_{3} \mathrm{~S}$, and minor contents of $\mathrm{C}_{2} \mathrm{~S}, \mathrm{C}_{3} \mathrm{~A}, \mathrm{C}_{4} \mathrm{AF}$ and gypsum. Its hydration products contains significant amount of portlandite, and minor content of ettringite. Similar to the behavior of $\mathrm{C}_{3} \mathrm{~S}$ in Type $\mathrm{K}$, hydration of Type II/ $\mathrm{V}$ cement is rapid in the first week, but significantly slows down after that.

\subsubsection{SEM observations}

To provide microscale morphology for the tested samples, SEM were conducted on the flexural-test samples, at both SE and BSE modes. To have a reliable knowledge about the microstructure, large numbers of images were collected and analysed. Here, representative images are shown in Fig. 12. As shown in Fig. 12(a), the hydrated matrix is composed of featureless paste and crystals embedded within. The crystals with large size and smooth cleavage (white arrow in Fig. 12(a)) are assigned to Portlandite, due to its unique morphology and abundance in XRD results. Some fibrillar products are observed within the paste and are assigned to ettringite needles, which exhibit small quantity of signals in the XRD results. The featureless paste is the anhydrous cement 


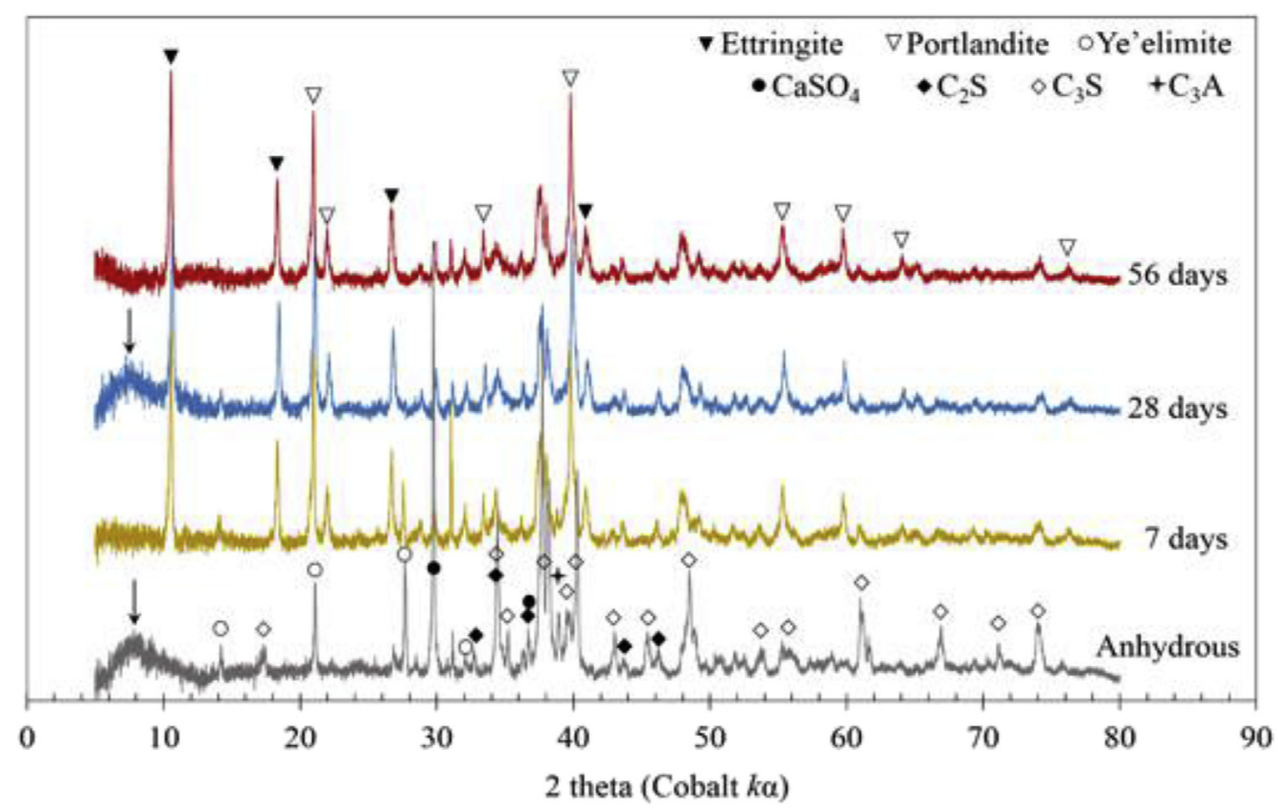

(a)

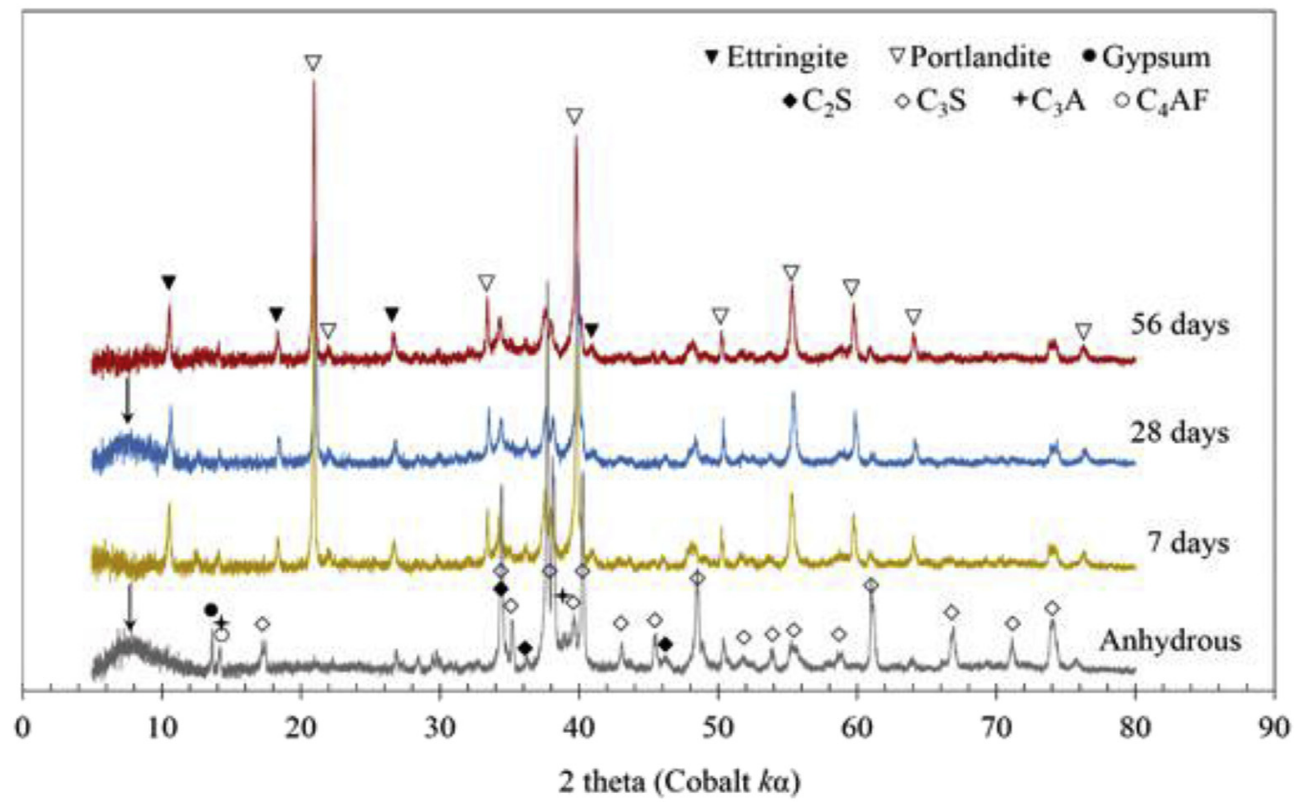

(b)

Fig. 11. XRD pattern of anhydrous cements and hydration products of both types of cement at different ages: (a) Type K cement, (b) Type II/V cement. The black arrows in the small 2-theta domain is the background peak from certain sample holders.

and the hydration product C-S-H gel. In general, hardened Type II/V paste resembles the microstructure of a typical hydrated matrix of OPC. As shown in Fig. 12(b), fibrillar crystals dominate the microscale morphology of Type $\mathrm{K}$ cement paste. This is consistent with XRD result that hydration product of expansive cement contains large quantity of ettringite. Ettringite in Type $\mathrm{K}$ cement paste grows to much larger size (length 15-30 $\mu \mathrm{m}$, and diameter 1-1.5 $\mu \mathrm{m}$ ), compared with the ettringite needles in OPC paste (length 3-5 $\mu \mathrm{m}$, and diameter $0.3-0.4 \mu \mathrm{m}$ ). The rapid formation of ettringite in expansive cement contributes to its volumetric expansion that was seen in drying shrinkage test results.

The microscale morphology of fiber embedment in Type $\mathrm{K}$ cement paste is also investigated. As shown in Fig. 13(a), on a fracture surface of mix containing $0.5 \%$ PVA fibers, a PVA fiber is half-embedded in the paste (red solid square). However the other end of the fiber (red dashed square) exhibits a large deformation, which could possibly be a fracture too. This indicates that the PVA fiber is very well embedded in the matrix, and therefore increases the resistance against cracking-opening. In Fig. 13(b), a tight bond between the paste and steel fiber is also observed - even after fracture, the paste is still closely attached to the surface of the steel fiber. The microstructure evidence therefore confirm that the mechanical bonding between two types of fiber and the paste is solid, and should significantly increase the fracture toughness of the composite. This can also contribute to the better performance of fiber pull-out resistance in mixes containing expansive cement.

To obtain a better estimation of the pore structure, BSE mode was 

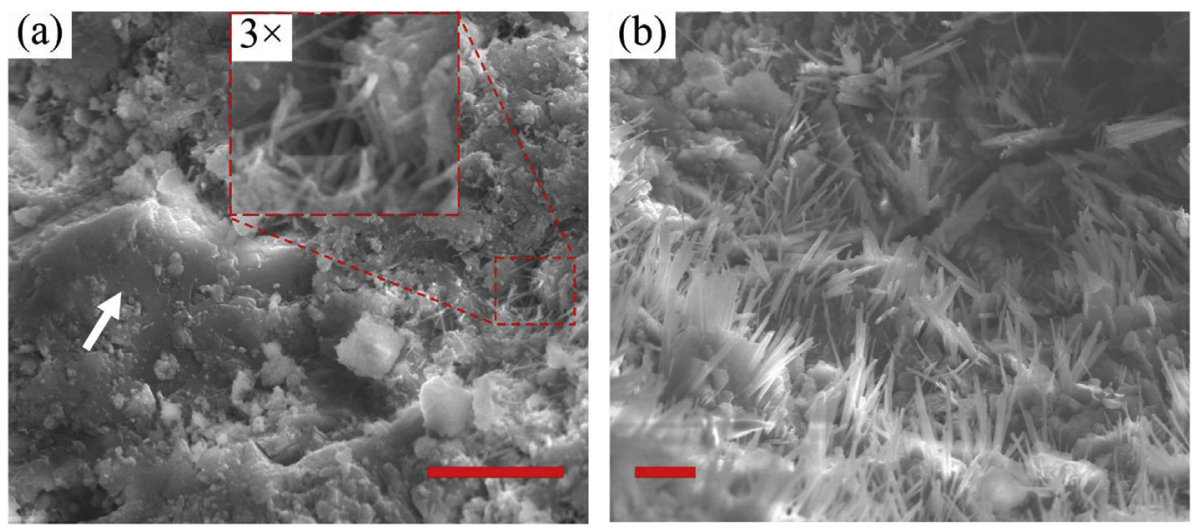

Fig. 12. Microscale morphology of: (a) Type II/V cement paste and (b) Type K cement paste after 28day curing. Scale bars are $10 \mu \mathrm{m}$. White arrow in (a) indicates the large and smooth cleavage of Portlandite crystals. A fibrillar morphology (red-dashed square) in (a) is magnified. (For interpretation of the references to colour in this figure legend, the reader is referred to the Web version of this article.)

applied to finely-polished surfaces of pastes, as shown in Fig. 14. In each image, there exist gaps between aggregates and paste, which is most likely generated during the polishing process and will not be discussed. In Fig. 14(a), pores of a several micron are universally ob-served in the paste of Mix 1 (Type II/V), whereas in (b) the paste of Mix 2 (Type K) cement appears much less porous. The matrix of Mix 3 also exhibit no visible pores. This can be attributed to the large volume of the Type K cement hydrates which efficiently fill the pore space. However, in the hardened paste of Mix 4 and 5 that contains PVA fibers, large pores are observed. There pores exhibit spherical shape, with diameter in the range of 10-100 $\mu \mathrm{m}$. In Table 2, it is shown that the workability of Mix 4 and 5 are worse than the other three mixes, even the additions of superplasticizer in these mixes are the highest. There-fore the observed pores in Mix 4 and 5 can probably be attributed to two reasons: 1) the honeycomb due to the low workability, and 2) the PVA fiber itself is black under SEM, and is accounted as pores. Mix 3 has the best workability and an intermediate dosage of superplastisizer, and it turns out that the paste of Mix 3 does not contain as many large pores as in Mix 4 and 5. Using software Image J, Fig. 14(a), (d) and (e) are converted to binary images with pores being highlighted and solids as background. The binary images are then processed with a 'particle analysis' plugin for size distribution analysis. The results are shown in Fig. 14(f). Most pores in Mix 1 have diameter smaller than $10 \mu \mathrm{m}$, with average value $\sim 3 \mu \mathrm{m}$. However in Mix 4 and 5 , the major contribution to porosity is from pores with diameter larger than $40-50 \mu \mathrm{m}$. The average pore diameters of Mix 4 and 5 are $\sim 60$ and $\sim 67$ $\mu \mathrm{m}$, respec-tively.

\subsection{Correlation between microstructural observation and engineering properties of concrete}

Concrete is a heterogeneous material consists of aggregate, cement paste, and pores that distributed with different sizes, and shapes [47]. The pore structure significantly affects the strength of concrete, and an increase in the porosity reduces the mechanical properties of concrete [48]. The results of microstructural observation by SEM method show that the replacement of OPC with Type $\mathrm{K}$ cement resulted in a reduction in the porosity of concrete. Additionally, the main hydration products of OPC and Type $\mathrm{k}$ cement were portlandite and ettringite, respectively. However, the mechanical properties of concrete produced with Type $\mathrm{K}$ cement were lower over those of the OPC mix. This result suggest that the presence of micro-cracks due to the formation of ettringite with expansion behavior may adversely affected the strength of concrete. The results further indicate that the water absorption of concrete con-taining Type $\mathrm{K}$ cement was lower than that of the OPC mix. This can be explained by the fact that the greater amount of ettringite developed in this mix, fills the pores, causes the discontinuity of pore network, and subsequently reduces the water absorption of concrete. Comparing the SEM images of FRC in BSE mode indicate that the addition of 1\% DHE steel fibers had insignificant influence on the porosity of concrete, while introducing PVA fibers notably increased the content and size of pores. The finding of this research reveal that the best performance among all FRC considered in this study was attained by the mix containing only DHE steel fibers. On the other hand hybridization of metallic fibers with PVA fibers resulted in a reduction in the mechanical properties of concrete. Additionally, the highest water absorption was attained by the mix containing higher amount of PVA fibers (i.e. Mix 4). This is in agreement with the pore structure of the corresponding mix. Therefore, slightly higher water absorption and lower mechanical properties of HyFRC compared to those of mix containing only DHE steel fibers can also be explained by the appearance of pores with larger size. However, it is worth noting that the dominant factor in this study that influences the mechanical properties of FRC is the fiber type.

\section{Conclusions}

This paper studied the effect of Type K cement on the mechanical, physical and microstructural properties of concrete. Also, the
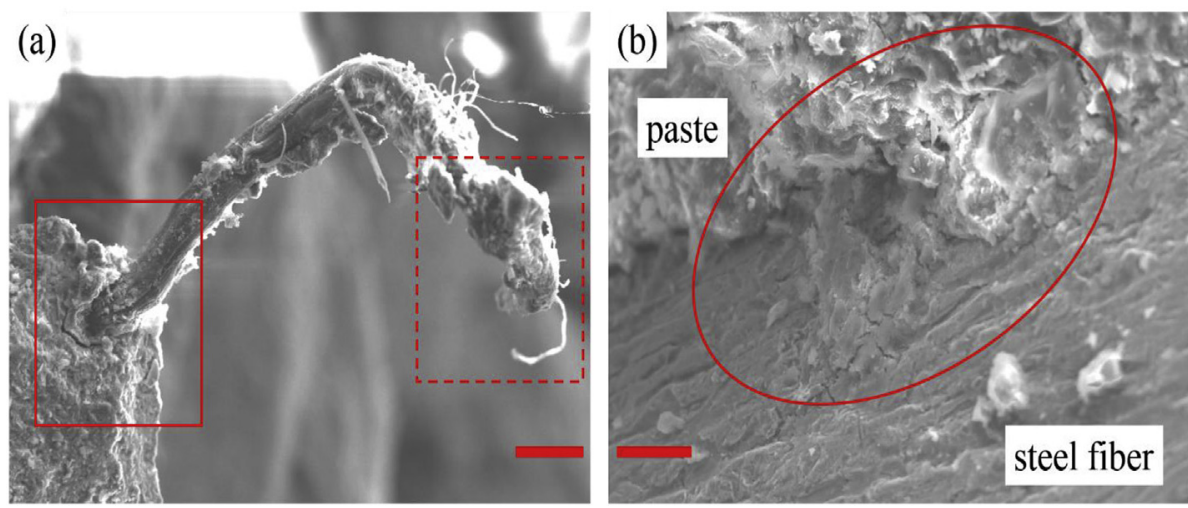

Fig. 13. Microscale morphology of: (a) DHE0.5 + PVA0.5 paste and (b) DHE0.5 + HE0.3 + PVA0.2 paste after 28-day curing. Scale bars are $20 \mu \mathrm{m}$. Red squares and circles indicate details of PVA fiber and steel fiber, respectively. (For interpretation of the references to colour in this figure legend, the reader is referred to the Web version of this article.) 

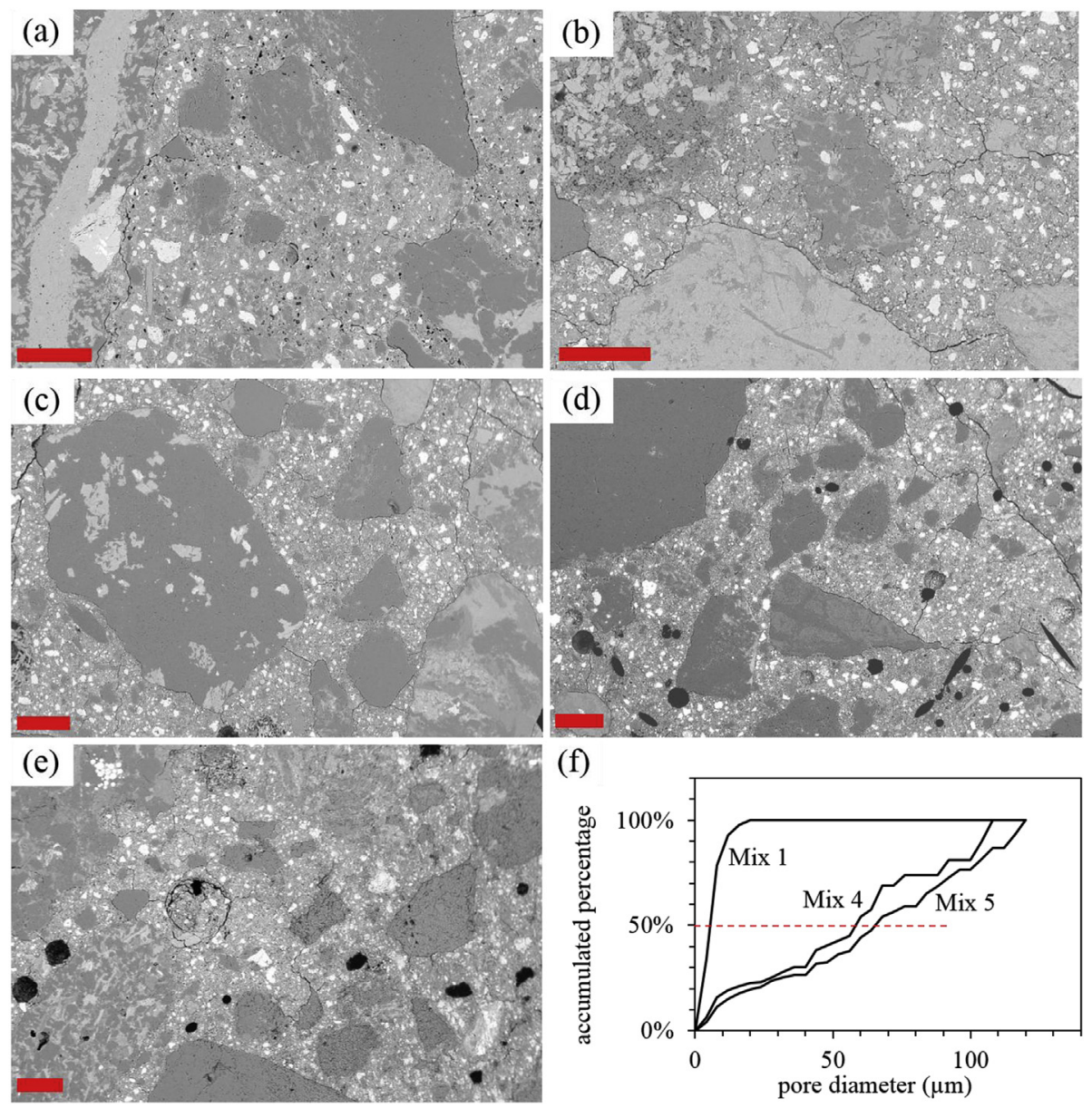

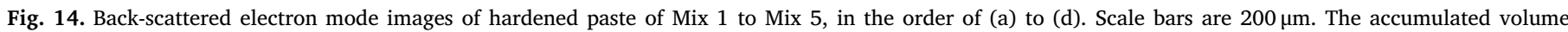
percentage of pores as a function of their pore diameter is shown (f), as calculated from (a), (d) and (e).

characteristics of HyFRC containing metallic and non-metallic fibers and fabricated with Type $\mathrm{K}$ cement was investigated. The following conclusions can be drawn from the experimental results:

1 The replacement of OPC with Type K cement has insignificant influence on the mechanical strength of concrete and it leads to almost similar compressive, splitting tensile and flexural strength.

2 A great expansion was occurred in samples containing expansive cement at 1 days. Thereafter, it compensates the shrinkage of concrete and leads to volume stability of concrete after 56 days. The early expansion of concrete fabricated with Type K cement can be attributed to the formation of high amount ettringite. On the other hand, the highest drying shrinkage was attained by the plain concrete made with OPC that shows $475 \mu \mathrm{m} / \mathrm{m}$ after 56 days.

3 The results indicate that the ultimate water absorption of mix containing Type $\mathrm{K}$ cement was reduced by $22 \%$ as a result of improved characteristics of cement past.

4 The replacement of OPC with Type K cement in mortars led to an increase of $26 \%$ in the pullout resistance of steel fibers. The reason of that can be attributed to the better chemical adhesion between fibers and cement matrix as a result of cement expansion and formation of self-prestress effect.

5 The microstructural analysis by means of XRD method show that the main hydration product of cement paste made with OPC and Type $\mathrm{K}$ cement is portlandite and ettringite, respectively. The SEM observation also demonstrate that the replacement of OPC with Type $\mathrm{K}$ cement improves the properties of cement matrix and leads to the appearance of ettringite needles with larger size compared to that of
OPC.

6 Introducing 1\% DHE steel fibers significantly increased the mechanical properties and particularly the flexural performance of concrete. With the addition of $1 \%$ DHE steel fibers the compressive, splitting tensile, and flexural strengths increased by $4 \%, 94 \%$, and $122 \%$, respectively at 28 days compared to those of corresponding mix without fibers.

7 A deflection hardening behavior was seen in the flexural performance of all HyFRCs considered in this study. This can be explained by the ability of DHE steel fibers to restrict the propagation of cracks due to their high elastic modulus and particular shape. Hybridization of DHE steel fibers with HE steel fibers or PVA fibers led to a reduction in the flexural performance of HyFRC.

8 The results of FRC indicate that hybridization of fibers is a promising way to reduce the shrinkage deformation of concrete. Among different FRC considered in this study, the lowest drying shrinkage was attained by DHE0.5 + HE0.3 + PVA0.2 mix. The inclusion of fibers also reduces the water absorption of concrete.

9 Irrespective to the type of cement, the addition of 1\% PVA fibers in mortars adversely affects the pull-out resistance of steel fibers. This can be related to the higher amount of voids around the hooked-end as a result of poor workability.

10 The SEM observation verifies the good bond between the fibers and cement matrix due to the expansion of Type K cement. Also, the BSE images show that voids with bigger size was formed in mixes containing PVA fibers compared to other mixes. 


\section{Acknowledgment}

The first author wishes to thank the generous support given by Professors Paulo J.M. Monteiro and Claudia P. Ostertag, which made this research possible. Administrative support provided by the Department of Civil \& Environmental Engineering at University of California, Berkeley is also gratefully acknowledged.

\section{References}

[1] K. Celik, C. Meral, M. Mancio, P.K. Mehta, P.J. Monteiro, A comparative study of self-consolidating concretes incorporating high-volume natural pozzolan or highvolume fly ash, Construct. Build. Mater. 67 (2014) 14-19.

[2] V. Afroughsabet, L. Biolzi, T. Ozbakkaloglu, High-performance fiber-reinforced concrete: a review, J. Mater. Sci. 51 (14) (2016) 6517-6551.

[3] D.P. Bentz, M.R. Geiker, K.K. Hansen, Shrinkage-reducing admixtures and early-age desiccation in cement pastes and mortars, Cement Concr. Res. 31 (7) (2001) 1075-1085.

[4] V. Corinaldesi, A. Nardinocchi, Influence of type of fibers on the properties of high performance cement-based composites, Construct. Build. Mater. 107 (2016) 321331.

[5] Q. Cao, Y. Cheng, M. Cao, Q. Gao, Workability, strength and shrinkage of fiber reinforced expansive self-consolidating concrete, Construct. Build. Mater. 131 (2017) $178-185$

[6] S.P. Shah, W.J. Weiss, W. Yang, Shrinkage cracking-can it Be prevented? Concr. Int. 20 (4) (1998) 51-55.

[7] F. Liu, S.L. Shen, D.W. Hou, A. Arulrajah, S. Horpibulsuk, Enhancing behavior of large volume underground concrete structure using expansive agents, Construct. Build. Mater. 114 (2016) 49-55.

[8] M.J. Oliveira, A.B. Ribeiro, F.G. Branco, Combined effect of expansive and shrinkage reducing admixtures to control autogenous shrinkage in self-compacting concrete, Construct. Build. Mater. 52 (2014) 267-275.

[9] S. Nagataki, H. Gomi, Expansive admixtures (mainly ettringite), Cement Concr. Compos. 20 (2-3) (1998) 163-170.

[10] J. Han, D. Jia, P. Yan, Understanding the shrinkage compensating ability of type K expansive agent in concrete, Construct. Build. Mater. 116 (2016) 36-44.

[11] ACI 223-98, Standard Practice for the Use of Shrinkage-compensating Concrete, (1998).

[12] P. Carballosa, J.G. Calvo, D. Revuelta, J.J. Sánchez, J.P. Gutiérrez, Influence of cement and expansive additive types in the performance of self-stressing and selfcompacting concretes for structural elements, Construct. Build. Mater. 93 (2015) 223-229.

[13] J.J. Park, D.Y. Yoo, S.W. Kim, Y.S. Yoon, Drying shrinkage cracking characteristics of ultra-high-performance fibre reinforced concrete with expansive and shrinkage reducing agents, Mag. Concr. Res. 65 (4) (2013) 248-256.

[14] M. Nili, V. Afroughsabet, Combined effect of silica fume and steel fibers on the impact resistance and mechanical properties of concrete, Int. J. Impact Eng. 37 (8) (2010) 879-886.

[15] A.A. Shah, Y. Ribakov, Recent trends in steel fibered high-strength concrete, Mater. Des. 32 (8) (2011) 4122-4151.

[16] S. Teng, Y. Liu, T.Y.D. Lim, Determination of fracture energy of ultra high strength concrete, Eng. Fract. Mech. 131 (2014) 602-615.

[17] C. Jiang, K. Fan, F. Wu, D. Chen, Experimental study on the mechanical properties and microstructure of chopped basalt fibre reinforced concrete, Mater. Des. 58 (2014) 187-193.

[18] N. Banthia, F. Majdzadeh, J. Wu, V. Bindiganavile, Fiber synergy in hybrid fiber reinforced concrete (HyFRC) in flexure and direct shear, Cement Concr. Compos. 48 (2014) 91-97.

[19] V. Afroughsabet, T. Ozbakkaloglu, Mechanical and durability properties of highstrength concrete containing steel and polypropylene fibers, Construct. Build. Mater. 94 (2015) 73-82.

[20] K. Behfarnia, A. Behravan, Application of high performance polypropylene fibers in concrete lining of water tunnels, Mater. Des. 55 (2014) 274-279.

[21] S.H. Park, G.S. Ryu, K.T. Koh, D.J. Kim, Effect of shrinkage reducing agent on pullout resistance of high-strength steel fibers embedded in ultra-high-performance concrete, Cement Concr. Compos. 49 (2014) 59-69.

[22] O.S. Banyhussan, G. Yıldıım, E. Bayraktar, S. Demirhan, M. Sahmaran, Deflectionhardening hybrid fiber reinforced concrete: the effect of aggregate content, Construct. Build. Mater. 125 (2016) 41-52.

[23] S.P. Yap, C.H. Bu, U.J. Alengaram, K.H. Mo, M.Z. Jumaat, Flexural toughness characteristics of steel-polypropylene hybrid fibre-reinforced oil palm shell concrete, Mater. Des. 57 (2014) 652-659.

[24] G. Jen, W. Trono, C.P. Ostertag, Self-consolidating hybrid fiber reinforced concrete: development, properties and composite behavior, Construct. Build. Mater. 104 (2016) 63-71.

[25] M.A.E.M. Ali, A.M. Soliman, M.L. Nehdi, Hybrid-fiber reinforced engineered cementitious composite under tensile and impact loading, Mater. Des. 117 (2017) 139149.

[26] W. Sun, H. Chen, X. Luo, H. Qian, The effect of hybrid fibers and expansive agent on the shrinkage and permeability of high-performance concrete, Cement Concr. Res. 31 (4) (2001) 595-601.

[27] V. Corinaldesi, A. Nardinocchi, J. Donnini, The influence of expansive agent on the performance of fibre reinforced cement-based composites, Construct. Build. Mater. 91 (2015) 171-179.

[28] H. Ma, H. Yu, W. Sun, Freezing-thawing durability and its improvement of high strength shrinkage compensation concrete with high volume mineral admixtures, Construct. Build. Mater. 39 (2013) 124-128.

[29] ASTM C 143/C 143M-15a, Standard Test Method for Slump of Hydraulic-cement Concrete, (2015)

[30] ASTM C 39/C 39M-03, Standard Test Method for Compressive Strength of Cylindrical Concrete Specimens, (2003).

[31] ASTM C 496/C 496M-11, Standard Test Method for Splitting Tensile Strength of Cylindrical Concrete Specimens, (2011).

[32] EN 14651, Test Method for Metallic Fibre Concrete-measuring the Flexural Tensile Strength (Limit of Proportionality (LOP), Residual), (2007).

[33] ASTM C 157/C 157M-08, Standard Test Method for Length Change of Hardened Hydraulic-cement Mortar and Concrete, (2014).

[34] ASTM C 642-13, Standard Test Method for Density, Absorption, and Voids in Hardened Concrete, (2013).

[35] J.G. Calvo, D. Revuelta, P. Carballosa, J.P. Gutiérrez, Comparison between the performance of expansive SCC and expansive conventional concretes in different expansion and curing conditions, Construct. Build. Mater. 136 (2017) 277-285.

[36] H. Shuguang, L. Yue, Research on the hydration, hardening mechanism, and microstructure of high performance expansive concrete, Cement Concr. Res. 29 (7) (1999) 1013-1017.

[37] V. Afroughsabet, L. Biolzi, T. Ozbakkaloglu, Influence of double hooked-end steel fibers and slag on mechanical and durability properties of high performance recycled aggregate concrete, Compos. Struct. 181 (2017) 273-284.

[38] J.Y. Wang, K.S. Chia, J.Y.R. Liew, M.H. Zhang, Flexural performance of fiber-reinforced ultra lightweight cement composites with low fiber content, Cement Concr. Compos. 43 (2013) 39-47.

[39] P. Balaguru, H. Najm, High-performance fiber-reinforced concrete mixture proportions with high fiber volume fractions, Materials Journal 101 (4) (2004) 281286.

[40] Venkateshwaran, A., Tan, K. H., \& Li, Y. Residual flexural strengths of steel fiber reinforced concrete with multiple hooked-end fibers. Struct. Concr., 1-14.

[41] Fib Bulletin 65, Model Code 2010-Final Draft vol. 1, (2010), pp. 234-247.

[42] B.K. Paul, M. Polivka, P.K. Mehta, Properties of fiber reinforced shrinkage-compensating concrete, Journal Proceedings 78 (6) (1981) 488-492.

[43] H.A. He, W. Dong, Z.M. Wu, Study on long-term expansive deformation of selfstressing concrete with combined restrictions of steel fibers and steel bar, Key Eng. Mater. 452 (2011) 533-536.

[44] S. Ioannou, K. Paine, L. Reig, K. Quillin, Performance characteristics of concrete based on a ternary calcium sulfoaluminate-anhydrite-fly ash cement, Cement Concr. Compos. 55 (2015) 196-204.

[45] M. Nili, V. Afroughsabet, Property assessment of steel-fibre reinforced concrete made with silica fume, Construct. Build. Mater. 28 (1) (2012) 664-669.

[46] I. Markovich, J.G.M. Van Mier, J.C. Walraven, Single fiber pullout from hybrid fiber reinforced concrete, Heron 46 (3) (2001) 191-200.

[47] R. Kumar, B. Bhattacharjee, Porosity, pore size distribution and in situ strength of concrete, Cement Concr. Res. 33 (1) (2003) 155-164.

[48] M. O'Farrell, S. Wild, B.B. Sabir, Pore size distribution and compressive strength of waste clay brick mortar, Cement Concr. Compos. 23 (1) (2001) 81-91. 